УДК 330.131 .7

\title{
КОНЦЕПТУАЛЬНЫЕ ПОДХОДЫ К УПРАВЛЕНИЮ РИСКАМИ СЛОЖНЫХ ОРГАНИЗАЦИОННО-ЭКОНОМИЧЕСКИХ СИСТЕМ: СИСТЕМАТИЗАЦИЯ И КРИТИЧЕСКИЙ АНАЛИЗ ${ }^{1}$
}

\author{
(C) 2012 г. Е. А. Кузвмин
}

\section{Уральский государственный экономический университет, г. Екатеринбург}

В статье автором обращено внимание на существование такой научной проблемы как определение «эталона» в управлении рисками. Именно для исключения такой проблемы, автором рассматриваются, систематизируются и критически анализируются существующие концепции риск-менеджмента, выявляются отличительные их признаки, выводятся предположения об их использовании в процессе формирования модели управления рисками. Помимо этого в исследовании уточняются понятия организачионно-экономических систем (ОЭС) и управления рисками ОЭС.

Ключевые слова: организационно-экономическая система; конщепџии управления рисками.

In this article the author drew attention to the existence of a scientific problem as the definition of «etalon» in risk management. This is to avoid such problems, the author discusses, systematized and critically analyzes existing concepts of risk management, identify their distinguishing characteristics are derived assumptions about their use in the process of risk management models. In addition, the study clarifies the concepts of organizational and economic systems (OES) and risk management OES.

Key words: organizational and economic system; concept of risk management.

\section{1. Введение}

Выстраивание управленческих решений относительно воздействия на риски и угрозы предполагает выбор базовой целевой установки, следование которой позволит достичь целей повышения эффективности и оптимизации функциональных процессов деятельности организационно-экономических систем.

Множественность, неоднозначность и субъективность целей эффективности и оптимизации выявляет такую важную и актуальную проблему как определение «эталона». Идеальное положение организационно-экономической системы, к которому оно должно стремиться вовсе не является столь очевидным и достижимым. Плюрализм восприятия эффективности и оптимальности, выдающиеся через различные экстерналии и интерналии, в большинстве случаев не позволяет однозначным образом утверждать, что организационно-экономическая система должна минимизировать все риски и свести их воздействие на нет. Вполне возможно, что система будет эффективна и других состояниях, когда риски, к примеру, будут на приемлемом уровне, что не предполагает их изначальную минимизацию.

Тем самым, в управлении рисками данная проблема развивается и переходит в проблему формирования целей стратегии воздействия на риски и угрозы, где главным звеном является определение конечного результата риск-менеджмента. Автор склонен считать, что известная в достаточной степени стратегия по минимизации рисков, которая

1 Работа выполнена при финансовой поддержке Российского гуманитарного научного фонда и Министерства промышленности и науки Свердловской области, проект № 11-12-66006a/У 
является устоявшимся стереотипом в видении преобладающего большинства ученых и специалистов, уже не столь состоятельна. На первый план все чаще выходят показатели полезности и ресурсообеспеченности, которые не вписываются в распространенное традиционное понимание рисков. Именно для целей расширения теоретических взглядов на проблему управления рисками автором и проводится данное исследование.

К этому стоит добавить и тот факт, что понятие сложной организационно-экономической системы на текущий момент в научном сообществе не является четко закрепленным. Трактовки понятия могут меняться в зависимости от контекста его применения и заложенных дефиниций в сущность организационно-экономических систем.

В рамках настоящего исследования автором предпринимается попытка обоснования возможности использование категории организационно-экономических систем применительно к систематизации и обзору концептуальных подходов к управлению рисками. Основание к этому служат несколько причин. Во-первых, управление рисками распространяется не только на конкретные субъекты хозяйствования, но должно внедряться систему управлением отраслевым и региональным развитием, в том числе на уровне национальной экономики. Во-вторых, как представляется, термин организационно-экономической системы возможно использовать для анализа маргинальных экономических единиц, как например существование в экономике проектов государственно-частного партнерства, которые трудно однозначным образом типизировать по признаку субъектности. Для этого автором в рамках исследования ставится научная задача по уточнению понятия организационно-экономической системы, аргументированному доказательству универсальности данного термина и возможности использования для целей обобщения концептуальных подходов управления рисками.

Безусловно, что формирование адаптированного механизма функционирования сложных организационно-экономических систем базируется на комплексном управлении рисками внутреннего и внешнего характера, обусловленными ситуациями изменчивости условий деятельности и неопределенности динамики последующего развития. Уточнение концептуальных подходов к управлению рисками сложных организационных систем является важной составляющей исследования для построения модели управления рисками.

Таким образом, в настоящем исследовании автор одновременно ставит и решает такие разные научные задачи как обоснование применимости понятия организационноэкономические системы, как универсальной дефиниции аналитической конструкции, и систематизация и критический анализ концепций управления рисками в отношении организационно-экономических систем.

\section{2. Организационно-экономические си- стемы в риск-менеджменте}

В ряде случаев в научной литературе понятия «организационно-экономическая система» и «организационно-экономический механизм» употребляется в равном значении, что является недопустимым, поскольку система базируется на механизме взаимодействия ее элементов, являющейся движущей основой системы. Определение организационно-экономического механизма А. А. Кульманом [12] является явным тому подтверждением: организационно-экономический механизм есть определенная совокупность или последовательность экономических явлений.

Емкое определение организационно-экономической системы дает В. О. Федорович [25], подразумевая под ней взаимозависимую совокупность элементов - организационно, экономически, а иногда и технологически связанных между собой подсистем более низкого уровня, обозначая при этом, что конечный результат деятельности каждого звена (или элемента) системы более низкого уровня служит начальным ресурсом для системы более высокого ранга. Данное определение в большей степени раскрывает организационную сторону системы, нежели ее экономическую составляющую. Для определения наиболее полного трактования организационно-экономической системы необходимо обраться к терминам, делающим акцент на экономических процессах.

Так, И. Н. Глухих [7, с. 127] определяет организационно-экономическую систему как организационную систему, участвующую в 
экономических процессах создания, распределения, обмена материальных благ. Однако трактование понятия организационно-экономической системы не включает возможное создание нематериальных благ (услуг, работ), которые могут предметом отношений между экономическими агентами. Для расширения области охвата организационно-экономических систем следует дополнить понятие, выдвинутое И. Н. Глухих сферой нематериального производства.

Таким образом, в целях исследования под организационно-экономической системой следует понимать сложную совокупность организачионно выстроенных структур (элементов системы), экономических процессов, форм и методов управления данными процессами в сфере материального и нематериального воспроизводства благ, с помошью которых реализуется конкретная экономическая парадигма. В соответствии с предложенным определением сложная организационно-экономическая система должна соответствовать ряду критериев, среди которых:

- неоднородность элементов организационно-экономической системы (элементы системы не должны иметь сходные между собой по всей совокупности организационную структуру, нормативную основу функционирования и институциональную форму подчинения/взаимоподчинения);

- наличие факторов влияния (на систему) и объектов влияния (из системы);

- объективность форм, методов и моделей управления процессами системы;

- определенность результатов функционирования системы;

- реализация воспроизводственного процесса;

- скоординированность целей элементов системы по достижению определенного результата функционирования системы;

- наличие масштабов деятельности системы;
— присутствие ограничений развития;

- наличие информационных и иных потоков ресурсов, связанных обратной связью.

Тем самым, по распределению значений критериев становится возможной типизация организационно-экономических систем на системы различного порядка. По мнению автора, можно выделить системы трех порядков - на уровне национальной экономики, на уровне отрасли или региона и на уровне хозяйствующих субъектов ${ }^{2}$.

Уточнение сущности сложных организационных систем, требует выработки позиции в отношении содержания риск-менеджмента как самостоятельного направления общей теории управления и принятия управленческого решения ${ }^{3}$.

\section{3. Обзор научной литературы (понятие «управление рисками»)}

Изучению вопросов принятия управленческих решений, разработке методологической базы, механизмов воздействия и конкретных инструментов риск-менеджмента в различное время занимались такие видные зарубежные и российские ученые как И. Т. Балабанов [1], К. В. Балдин [2], М. Г. Лапуста, М. Л. Разу [24], В. Н. Вяткин, В. А. Гамза, Ю. Ю. Екатеринославский, П. Н. Иванушко [5], В. И. Авдийский, В. А. Москвин [15], П. Г. Грабовый, С. Н. Петрова, С. И. Полтавцев, К. Г. Романова, Б. Б. Хрусталёв, С. М. Яровенко [8], Б. А. Райзберг [19], М. А. Рогов [20], Г. В. Чернова, А. А. Кудрявцев [26], J. R. Arrington [29], T. L. Barton, W. G. Shenkir, P. L. Walker [3], P. L. Bernstein [30], F. Knight и др.

В научном сообществе понятие «управление рисками» используется в широком и узком смысле в зависимости от контекста применения данного понятия и объекта, к которому оно направлено. В широком смысле управление рисками является наукой (дисциплиной) изучающей процессы функциони-

2 Сложные организационно-экономические системы, основываясь на уровневой организации экономики, можно подразделить на организационно-экономические системы 1-го, 2-го и 3-го порядка. Системы первого порядка функционируют на макроуровне представляя собой обособленную национальную или межрегиональную (межтерриториальную) экономику; системы 2-го порядка ограничиваются экономическими процессами, протекающими в отраслевом или межтерриториальном разрезе; системы 3-го порядка представляют собой организационные объекты с большим количеством элементов (субъектов) и распространенным масштабом деятельности.

3 Здесь и далее для исключения двусмысленности автор использует как тождественные понятия «риск-менеджмент» и «управление рисками». 
рования экономических агентов в условиях риска и неопределенности. В узком смысле управление рисками акцентирует внимание на конкретный субъект и объект деятельности, включающее процессы разработки специальных мер и мероприятий по снижению негативного воздействия от любых случайных событий, способных повлечь за собой убытки для хозяйствующего субъекта.

Анализ научной литературы, посвященной управлению рисками, выявил ряд ключевых составляющих понятий «управления рисками» в трактовке различных авторов. К данным составляющим относятся:

- процессный характер (управление рисками не является разовой процедурой, комплекс действий по управлению рисками должны быть встроены в общие корпоративные процессы хозяйствующего субъекта);

- возможность получить нежелательные последствия при реализации риска (риск по своей природе несет вероятные угрозы и убытки для объекта, на который риск направлен);

- вероятностный характер (проявление риска носит неопределенный стохастический характер, риск-событие проявляется с некоторой вероятностью и не может быть носить четкого детермированного определения);

- нивелирование вероятных последствий (процесс управления рисками направлен на снижение неблагоприятного их влияния как до момента проявления, так и после);

- наличие системы ограничений (процесс управления рисками испытывает воздействие системы ограничений в виде временного горизонта, масштабов деятельности субъекта хозяйствования, ресурсов и др.);

- деятельность, предпринимаемая субъектом управления, для составления плана превентивных и целевых мероприятий по предупреждению рисков, а также мероприятий по снижению последствий от проявления ряда рисков.

В работе А. А. Кудрявцева «управление рисками» является процессом принятия и выполнения управленческих решений, которые минимизируют неблагоприятное влияние на организацию или лицо убытков, вызванных случайным событием [11]. Несколько иначе трактуют понятие «управление рисками» Г. Н. Гипич и Ю. М. Чинючин [6], главным образом выделяя общественно-экономическую функцию управления рисками, которая реализуется через распределение (перераспределение) ресурсов, используемых для нивелирования различных рисков: управление рисками - процесс оптимального распределения затрат на снижение различных видов риска в условиях ограниченности экономических ресурсов общества, обеспечивающий такой уровень безопасности населения и окружающей среды, какой только достижим в существующих в данном обществе экономических и социальных условиях.

Приведение ряда понятий «управления рисками» указывает на наличие разнообразных подходов к пониманию и трактованию процесса снижения рисков. Тем самым, органическая совокупность составляющих управления рисками как процесса в узком смысле, дает основания для оригинальной формулировки понятия «управления рисками» в отношении организационно-экономических систем.

Управления рисками (организаџионноэкономических систем) - взаимосвязанныи комплекс прочессов, направленных на снижение вероятности возникновения, уровня значимости и последствий проявления рисков путем практической реализачии спечиальных мероприятий, принятия превентивных мер, внедрения адаптированных методов своевременного обнаружения и предотвращения рисков на основе соотнесения оптимального распределения затрат по мероприятиям, эффектов от их осуществления, а также оченке предельной полезности реакции на риск.

Предложенное автором определение управления рисками (проектов государственно-частного партнерства) находит свое подтверждение в разобщенном определении управления рисками, выдвигаемое экспертами консалтинговой компании АксионБКГ [17], и рисков, применительно к государственно-частному партнерству, сформулированного A. G. Straus [33]. Обоснованность авторской трактовки позволяет перейти к рассмотрению эволюционного развития концепций управления рисками в целом для сложных организационно-экономических систем. 
4. Систематизация и критический анализ концепций риск-менеджмента

Идентификация теоретических концептуальных подходов управления рисками сложных организационно-экономических систем исходит из сформированных концепций управления рисками. Концептуальные подходы (концепции) образуют органический комплекс методов и инструментов воздействия на риски сложных организационно-экономических систем. Опорным моментом концепций управления рисками является понимание целей управления и отображение сущности риска применительно к самой системе.

Эволюция развития теорий управления рисками позволила выделить следующие концепции риск-менеджмента сложных организационно-экономических систем, ставших предметом исследования:

- классическая концепция минимизации риска;

- неоклассическая концепция предельной полезности от управленческого решения в условиях риска;

- концепция приемлемого риска;

- концепция риска как ресурса;

- интегрированная концепция управления риском;

— концепция всеобщего риска.

\section{1. Классическая кониепџия минимиза-} циии риска

Классическая концепция минимизации риска оперирует исследованиями Дж. С. Милля [14] и Н. У. Сениора, которые четко отождествляли риск с некоторыми негативными последствиями для лица, принимающего управленческое решение. Тем самым, риск в данной концепции воспринимается как абсолютно негативная составляющая экономической деятельности хозяйствующих субъектов организационно-экономической системы. Определения категории «риск» в концепции носят характер неблагоприятного результата управленческих действий. Группа категорий наиболее подходящих для понимания сущности риска в данной концепции, выделяется автором как «результирующая», среди определений категории риск можно представить трактовки, выдвигаемые В. А. Гамза, Т. Бачкаи, Г. Б. Клейнером, М. Г. Лапуста и др.
Методы управления рисками в концепции минимизации риска ориентированы на сведение уровня риска до наименьшего возможного предела. В качестве критерия эффективности методов концепции выбираются показатели, отражающие изменении уровня риска, как то: вероятность негативного исхода событий, или уровень потерь (убытков) при заданной вероятности нежелательного события. Эффективность методов в данной концепции оценивается через динамику уровня риска: методы тем эффективнее, чем ниже риск.

Концепция минимизации риска построена на формальной логике принятий управленческих решений, характеризующихся отсутствием риска. Данное положение концепции объясняет ее простоту и универсальность применения. Однако, рассматривая и анализируя поведение субъекта управления рисками стоит отметить, управленческие решение, в которых риски отсутствует или минимальный, приводят к посредственным результатам для самой организационно-экономической системы. Возможность использования концепции ограничивается парадоксом «убыток-риск», который имеет двойственную природу и может быть выражен также как «доходность-риск». Парадокс состоит в том, что принятие управленческого решения с высоким риском приводит к повышению вероятного ущерба (убытков) от данного решения, однако это же решение может привести к получению высоких доходов.

Путь выбора решения с наименьшим уровнем риска может быть проведен как через отбор альтернатив с определенными характеристиками риска, так и через организацию специальных мероприятий. Оценка и сопоставление затрат на организацию и проведение подобных специальных мероприятий в рамках данной концепции, отражают важный критерий эффективности антирисковых действий: затраты по минимизации риска не должны превышать вероятных убытков от наступления нежелательного события.

Учитывая что, в объективной реальности практически не существует случайных событий, вероятность проявления которых равна нулю, так того, что уровень риска можно уменьшить да аналогичного значения. Но, несмотря на данное обстоятельство, проведение специальных мероприятий или выбор 
альтернативы с наименьшим уровнем риска может привести к ситуации, когда значимость и существенность риска достигнет такого значения, что последствия от его проявления не будут относиться к катастрофическим, что позволит сохранить целостность организационно-экономический системы и ее функциональность.

Таким образом, концепция минимизации риска может и должна рассматриваться для ряда ситуаций как приоритетная с установлением цели по снижению риска до некоторого приемлемого уровня, с понимаем того, что минимизировать риски до абсолютного минимального значения является не возможным.

4.2. Неоклассическая концеепция предельной полезности от управленческого решения в условиях риска

Основателями неоклассической концепции предельной полезности от управленческого решения в условиях риска и неопределенности являются ученые А. Маршал [13] и А. С. Пигу [16]. Согласно их подходу, риск рассматривается как статистическая характеристика отклонения ожидаемой доходности, выраженной через показатели эконометрического анализа (дисперсия, среднее квадратическое отклонение и др.). Концепция также поясняет, что действия лица, принимающего управленческие решения, продиктованы основополагающими принципами предельной полезности в условиях неопределенности.

Сущность принципа предельной полезности в условиях неопределенности и риска заключается в выборе такого альтернативы их имеющегося набора той альтернативы, в которой риск достижения равного положительного эффекта (в сравнении с другими альтернативами) будет минимальный. Оценка риска в альтернативах, как это уже было отмечено, происходит при анализе возможных отклонений.

В концепции предельной полезности от управленческого решения в условиях риска и неопределенности разрешение парадокса «доходность-риск» проявляется в полной мере: хозяйствующий субъект идет на риск в целях получения некоторого уровня дохода при условии, что риски выбранной альтерна- тивы меныше рисков других возможных альтернатив. Данное свойство управленческого поведения было отмечено Дж. М. Кейсом [32, c. 202], который назвал подобное поведение «склонность к риску». Феномен «склонности к риску» раскрывается в том, что учет фактора удовлетворения от риска, приводит к выводы, что ради ожидания большего дохода, лицо, принимающее управленческие решения, может пойти на больший риск.

Как и все основные последователи и основатели концепции предельной полезности от управленческого решения в условиях риска и неопределенности, Дж. М. Кейнс связывал категорию риска с вероятностью отклонения от поставленных целей. Развивая идею Дж. М. Кейнса о включении в стоимость затрат, связанных с риском, можно уточнить, что альтернативы отражающие некоторую доходность, на которую рассчитывает субъект управления, должны включать так называемые «издержки риска». В противном случае, сопоставление издержек риска с альтернативной доходностью, может привести к выводу об отказе от риска и, соответственно, отказе от выбора альтернативы.

\section{3. Концеепциия приемлемого риска}

Основоположником концепции приемлемого риска является Б. Н. Прокофьев [18], который отметил свойство приемлемости риска в своих первых публикациях, посвященных концепции приемлемого риска. Концепция стала ответом на низкоэффективную реализацию классической концепции минимизации риска, как универсального наборе методов управления рисками, в том числе для разрешения противоречий парадокса «доходность-риск».

Практическое первое применение концепции приемлемого риска было предпринято в Нидерландах [34] в рамках государственной экологической политики. Методология оценки, анализа и управления рисками, базирующаяся на концепции приемлемости риска была использована для формирования мероприятий по повышению экологической безопасности территориального образования, в котором наблюдается повышенная концентрация промышленных объектов. Нормативное закрепление концептуальных положений приемлемости риска в целях их 
последующего практического использования было осуществлено также в Нидерландах в рамках Memorandum Course of national policy on environmental protection (Меморандума «Курс национальной политик по защите окружающей среды» [23]). Вместе с тем, явление активной производственно-хозяйственной деятельности относится к характерным проявлениям сложных организационноэкономических систем по критерию масштабов деятельности.

Сущность концепции заключается в восприятии риска, который, в отличие от концепции минимизации риска должен быть снижен не до уровня его полного или частичного отсутствия, а до некоторого приемлемого уровня, при котором производственно-хозяйственная деятельность экономических агентов организационно-экономической системы не будет претерпевать качественных изменений. Понятие термина «приемлемый риск» использовалось в других более ранних концепциях, однако приемлемость как критериальный уровень эффективности ранее не рассматривался. В зависимости от понимания природы риска изменяется и понимание приемлемости риска.

Большинство научных публикаций используют понятие «приемлемость риска» в контексте обеспечения безопасности деятельности или безопасности состояния системы для её субъектов (через механизм обратной связи действия - управленческого решения - и результата действия). Исследованием трактовок понятия «приемлемости риска» в научной литературе приводит к использованию наиболее емкого и полного его трактования, предложенного Г. Н. Гипич и Ю. М. Чинючиным. Согласно их пониманию риска, приемлемый риск - это такой уровень риска, который является оправданным с точки зрения экономических и социальных факторов, то есть с которым общество [организационно-экономическая система] готово мириться ради получения определенных благ в результате своей деятельности [6].

Как целостная концепция, основу которой положил Б. Н. Прокофьев для российской школы научного управления риском, получила свое воплощение в исследованиях и работах других ученых несколько позже. Развернутые положения концепции приемле- мости риска нашли сове отражение в трудах Р. М. Качалова [9], Г. Б. Клейнера, В. Л. Тамбовцева [10] и других видных ученых.

Раскрытие положений концепции приемлемого риска, автором предлагается в виде структурированной табл. 1.

Обращая внимание, что понятие хозяйственного риска используется для экономических агентов (предприятий и организаций), значимость концепции для общей теории управления рисками не снижается. Направленность концепции приемлемого риска на хозяйствующие субъекты подчеркивает роль внутренних рисков в процессе их деятельности. Однако, несмотря на микроэкономический смысл концепции, затрагивающий субъектов производственно-хозяйственных отношений, концепция хорошо себя зарекомендовала в управлении рисками на макроуровне, что относится к предмету сложных организационно-экономических систем.

Сопоставительный анализ концепции приемлемого риска с теоретическими воззрениями общей теории экономического риска, отражает сходные положения в части позиций наличие альтернатив в принятии управленческого решения; проявление риска объективно обусловлено неопределенностью последствий предпринимаемых действий (управленческих решений); наличием рисков в любых действиях или событиях. Схожие черты концепции приемлемого риска дают основания для выделения отличий, благодаря которым концепция сформировалась как единый механизм управления рисками. Важным отличием является разделение стартового риска и финального, раздельное управление которыми может привести большим результатам эффективности. Позиция концепции по страновым и финальным рискам находят отклик в работах В. И. Авдийского и В. М. Безденежных, которые отмечали наличие исходной, переходной и конечной неопределенности.

Противопоставлением концепции минимизации риска является направление управляющего воздействия, когда уровень риска (в концепции приемлемого риска) должен быть уменьшен не до нулевого значения или приближенного к нему, а до приемлемого уровня.

Крайности позиций концепции минимизации риска связанные с использованием 
Таблица 1

Положения концепции приемлемого риска ${ }^{1}$

\begin{tabular}{|c|c|c|}
\hline $\begin{array}{l}\text { № } \\
\Pi / \Pi\end{array}$ & Признак & Положение концепции \\
\hline 1 & Сущность риска & $\begin{array}{l}\text { Хозяйственный риск - это объективное свойство целенаправ- } \\
\text { ленной деятельности хозяйствующего субъекта }{ }^{2}\end{array}$ \\
\hline 2 & \multirow{3}{*}{ Природа риска } & $\begin{array}{l}\text { Хозяйственный риск обусловлен объективными причинами: не- } \\
\text { полнотой информации о прошлом и настоящем, а также неопре- } \\
\text { деленностью будущего }\end{array}$ \\
\hline 3 & & $\begin{array}{l}\text { Хозяйственный риск производственного предприятия, действу- } \\
\text { ющего на рынке ресурсов, товаров и услуг, в той или иной мере } \\
\text { присутствует всегда, то есть уровень хозяйственного риска ни- } \\
\text { когда не бывает нулевым }\end{array}$ \\
\hline 4 & & $\begin{array}{l}\text { Хозяйственный риск возникает там, где принимается решение о } \\
\text { выборе одного из вариантов действий [управленческое решение] }\end{array}$ \\
\hline 5 & $\begin{array}{l}\text { Последствия } \\
\text { риска }\end{array}$ & $\begin{array}{l}\text { Хозяйственный риск проявляется в возможности нежелательно- } \\
\text { го развития событий и отклонения от преследуемой цели хозяй- } \\
\text { ственной деятельности предприятия }\end{array}$ \\
\hline 6 & $\begin{array}{l}\text { Характеристика } \\
\text { последствий } \\
\text { риска }\end{array}$ & $\begin{array}{l}\text { Нежелательное развитие событий и нежелательное отклонение } \\
\text { от преследуемой хозяйственной цели сопряжены с потерями } \\
\text { (ущербом) для хозяйствующего субъекта }\end{array}$ \\
\hline 7 & \multirow{2}{*}{ Мера риска } & $\begin{array}{l}\text { Уровень хозяйственного риска - субъективная характеристика; } \\
\text { она отражает размер ущерба для предприятия (по его оценке), } \\
\text { вызванного нежелательным развитием событий, обусловленным } \\
\text { действием (проявлением) факторов риска при принятии данного } \\
\text { хозяйственного решения }\end{array}$ \\
\hline 8 & & $\begin{array}{l}\text { Уровень хозяйственного риска можно измерить разными спосо- } \\
\text { бами, например, оценив материальные последствия нежелатель- } \\
\text { ного развития события, ставших результатом проявления нек-- } \\
\text { торого фактора хозяйственного риска, и степень реальности того } \\
\text { или иного варианта (направления) развития событий }\end{array}$ \\
\hline 9 & Виды риска & $\begin{array}{l}\text { Следует различать стартовый и финальный уровни риска, то } \\
\text { есть тот итоговый уровень риска, который по расчетам останет- } \\
\text { ся некомпенсированным после разработки и принятия специаль- } \\
\text { ных мер по его снижению }\end{array}$ \\
\hline 10 & \multirow{2}{*}{$\begin{array}{l}\text { Изменяемость } \\
\text { риска }\end{array}$} & $\begin{array}{l}\text { На уровень хозяйственного риска можно воздействовать, умень- } \\
\text { шать его значение, то есть уровнем хозяйственного риска можно } \\
\text { в некоторых пределах управлять }\end{array}$ \\
\hline 11 & & $\begin{array}{l}\text { Существует уровень риска, который [субъект управления] может } \\
\text { назвать в качестве приемлемого для данного производственного } \\
\text { предприятия в данной хозяйственной ситуации }\end{array}$ \\
\hline
\end{tabular}


Окончание таблицы 1

\begin{tabular}{|l|l|l|}
\hline 12 & $\begin{array}{l}\text { Управление } \\
\text { риском }\end{array}$ & $\begin{array}{l}\text { Существует возможность уменьшить уровень хозяйственного } \\
\text { риска до приемлемого значения, затратив на антирисковые ме- } \\
\text { роприятия некоторые ресурсы (материальные, финансовые и } \\
\text { др.) }\end{array}$ \\
\hline 13 & & $\begin{array}{l}\text { Если стартовый уровень риска некоторого варианта хозяйство- } \\
\text { вания пренебрежимо мал, это может означать, что данный вари- } \\
\text { ант решения не несет в себе новизны или существенных преи- } \\
\text { муществ (выгод) }\end{array}$ \\
\hline 14 & \multirow{5}{*}{ Границы риска } & $\begin{array}{l}\text { Больший уровень риска, как правило, сопряжен с надеждой на } \\
\text { больший успех, но и с опасностью больших потерь (ущерба) }\end{array}$ \\
\hline & $\begin{array}{l}\text { Уровень хозяйственного риска оригинальной, неапробирован- } \\
\text { ной бизнес-идеи, как правило, выше, чем для стандартных, ти- } \\
\text { повых, рутинных решений. Сознательными, рациональными } \\
\text { действиями (риск-менеджментом) этот уровень иногда можно } \\
\text { уменьшить до приемлемого значения }\end{array}$ \\
\hline
\end{tabular}

1 Составлено автором на основе результатов исследований и по работам Р. М. Качалова, Г. Б. Клейнера, В. Л.Тамбовцева.

2 Под хозяйственным риском следует понимать коммерческие (экономические) риски деятельности экономического агента организационно-экономической системы.

специальных мер без соизмерения затрат и возможных убытков от практической реализации рисков, решаются в концепции приемлемого риска путем рациональности сопоставления эффектов и издержек по достижению данных эффектов.

Однако, как и в других концепциях, риск отождествляется исключительно с возможным ущербом для деятельности хозяйствующего субъекта, а положения концепции не дают возможности оценить вероятный доход от принятий управленческого решения при заданном уровне риска в случае его позитивной реализации 4 .

Такое понимание концепции складывается из-за положения, где уровень риска оценивается и связывается исключительно с потерями. Возможность позитивной реализации риска предусмотрена в положении относительно большого уровня риска, когда (как правило), больший уровень риска сопряжен с надежной на больший успех, но с опасностью больших потерь.

Вместе с тем, в концепции приемлемого риска будет невозможным решение научной задачи по определению возможности полу- чения дополнительного дохода в результате управленческого решения в условиях риска и неопределенности. Тем самым, можно утверждать, что концепция требует совершенствования и дальнейшего развития.

\section{4. Концепџия риска как ресурса}

В концепции риска как ресурса делается довольно убедительная попытка нивелировать трудности концепции приемлемого риска, которая не принимала во внимание возможность использования изменений качественных свойств риска для получения дополнительного дохода (выгоды).

Концепция была выдвинута М. А. Гринфилдом [31], ряд ее принципиальных положений были адаптированы и раскрыты в работе А. Б. Секерина [21], который уточнил математический процесс управлений рисками в данной концепции и научно обоснованно предложил объединить концепцию риска как ресурса, концепцию приемлемого риска и концепцию минимизации риска в виде новой концепции - интегрированной концепции управления риском.

Сущность концепции управления ри-

4 Под позитивной реализацией риска подразумевается наступление события без отрицательных последствий для хозяйствующего субъекта или событий, имеющих положительное влияние. 
сками как ресурсом заключается в том, что управление рисками организационно-экономических систем должно быть идентичным управлению ресурсами в классической теории менеджмента. В работе М. А. Гринфилда делается акцент на эффективности затрат, направляемых на реализацию мероприятий по снижению уровня риска. Главный постулат концепции раскрывается в том, что оптимизация затрат на управление риском должна осуществляться путем сопоставления их с предельными издержками и доходами, где в качестве предельных издержек выступают затраты на антирисковые мероприятия, а в качестве доходов - величина потерь, на которую удалось снизить уровень подверженности риску, то есть предотвращенные вероятные потери.

Одновременно с этим, концепция использует позитивную реализацию риска как дополнительный рычаг. В ситуации, когда величина затрат является идентичным, выбор альтернативы с большим уровнем риска и, соответственно, с большим потенциальным доходом воспринимается как адекватное решение по повышению эффективности от затрат в случае положительной реализации риска, но при этом субъект управления принимает на себя равные вероятные убытки, что качественным образом отличает логику принятия управленческих решений от ранее рассмотренных концепций управления рисками организационно-экономических систем.

Развитие концепции риска как ресурса многими учеными определяется в направлении исследования ресурсо-подобных рисков, то есть рисков, которыми можно управлять как ресурсам. Является очевидным, что не все риски являются ресурсо-подобными, их выявление и возможность оценки, для последующего принятия управленческого решения является перспективным и актуальным направлением развитие теории риск-менеджмента в рамках данной концепции.

Идентификация ситуаций, когда увеличение риска, является лучшим вариантом из имеющихся альтернатив (в том числе снижение риска), включается в сферу определения ресурсо-подобных проявлений рисков в организационно-экономических системах. Вопрос выявления ресурсно-подобных рисков решается путем применения критериев, по которым риск может считаться ресурсо-подобным. К данным критериям относятся следующие: повышение уровня риска приводит к возрастанию позитивного эффекта; эффект возрастает нелинейно с насыщением до определенного предела, после которого дальнейший рост риска приводит к снижению дополнительного эффекта и перехода данного позитивного эффекта в негативный; процесс управления ресурсо-подобным риском характеризуется поддержанием заданного уровня оптимальности; управление ресурсо-подобным риском носит вариативный характер, не исключающий отказ от управления - выбора управленческого решения.

Как это уже было отмечено, позицию по совершенствованию концепции, выражают различные ученые, среди которых А. Б. Секерин, являющийся основателем интегрированной концепции управления риском.

\section{5. Интегрированная кониепиия управ-} ления риском

Концепция, предложенная А. Б. Секериным [22], является комбинацией и усовершенствованием трех концепций - концепции минимизации риска, концепции приемлемого риска и концепции риска как ресурса. Основу концепции составляют следующие положения:

- риском является характеристикой ситуации принятия решения в ходе экономической деятельности, связанной с субъективной оценкой субъектом принятия решений последствий влияния факторов неопределенности на результаты принимаемого решения с точки зрения благоприятного и неблагоприятного влияния;

- базовым признаком отличия ситуации неопределенности от рисковой ситуации является признак наличия четких предпочтений субъекта управления, с вязанных с его целями, которые в конечном итоге определяются его экономическими интересами;

- под неопределенностью понимается ситуация, когда субъект управления либо не обладает информацией, каковы возможные последствия принимаемых их решений, либо не имеет сведений о том, какие их последствия являются более благоприятными и небла- 
гоприятными по отношению к поставленной цели;

- риск объединяет в себе величину неопределенности ситуации и экономического интереса субъекта управления;

- уровнем риска является оценка возможных последствий рассматриваемого решения, которая в агрегированном виде отражает меру реальности наступления как благоприятных, так и неблагоприятных последствий, а также размеры возникающих при этом потерь или выгод;

- управленческое решение обладает некоторой нелинейной функцией полезности, при которой управленческая альтернативы тем предпочтительные, чем выше ее полезность;

— каждое управленческое решение, входящее в полигон альтернатив, обладает набором характеристик - оценкой уровня риска, стоимостной оценки ресурсов, необходимых для реализации решения;

- выбор управленческого решения стоится на сопоставлении агрегированной полезности и коэффициента риска, отражающего отношение потерь и выгод, который изменяется по функции полезности в координатах «риск-затраты».

Главным составным элементом интегрированной концепции управления риском является ресурсоемкость рисков, аналогом оценки которой в концепции выступает коэффициент риска. Динамика изменения дополнительной единицы выгод (дохода) на величину потерь и отражает ресурсоемкость риска.

Схожесть положений интегрированной концепции управления риском с описанными ранее концепциями отражает преемственность базовых теоретических представлений, однако вместе с тем, в концепции предлагается и научно обосновывается подход, сочетающий в себе ресурсное представление о риске и выборе управления решения с подходом оценки полезности управленческого воздействия и рисков, которое данное воздействие в себе содержит.

Интегрированная концепция управления рисками стала одной из концепций, объединяющей и дополняющей теоретические взгляды на риски и управления им в рамках одного целостного подхода. Сочетание достоинств положений концепций, составляющих ее научный базис, и предложений А. Б. Секерина к решению сложностей им присущих, дает основания для активного практического использования интегрированной концепции управления рисками в организационно-экономических системах.

\section{6. Кониеепиия всеобщего риска}

Научный подход к формированию концепции всеобщего риска был заложен О. Н. Яницким $[27 ; 28]$, который высказал предположение о том, что риск включает не только экономические потери, непроизводительные издержки хозяйствующих субъектов, но и его ресурс. В этом плане, концепция в ряде моментов перекликается с положениями концепции риска как ресурса.

В этой связи определение экономики всеобщего риска, данное Н. Д. Бубликом [4], демонстрирует взаимосвязь между производством и использованием ресурсов. Так, под экономикой всеобщего риска Н. Д. Бублик понимал нарушение баланса в системе производства и использования ресурсов, необходимых для устойчивого развития общества.

Вместе с этим, Н. Д. Бублик выдвигает ряд положений, относящихся к концепции всеобщего риска:

1. Любой потребляемый обществом ресурс есть продукт двойного назначения, то есть всякий произведенный обществом товар, благо потенциально рискогенны.

2. Производство рисков нарушает баланс функций среды как «поглотителя», так и «побудителя» риска. На оздоровление среды как накопителя потерь, отходов производства товаров необходимо тратить соответствующие ресурсы. Среда как высокая концентрация результатов производства рисков и, собственно, само производство рисков становится объектом инноваций и «поглотителем» ресурсов.

3. Доступные ресурсы в каждый конкретный момент времени ограничены, поэтому их мобилизация есть столкновение интересов и борьба. Задача государства - оптимизировать распределение ресурсов между производствами знаний, благ и рисков.

4. Ряд разновидностей рисков являются 
полезными ресурсами для любого производства.

При этом, риск может являться объектом управления в рассмотрении его как ресурсного объекта, содержащего в себе возможность поддержания баланса между производством благ и производством потерь.

Систематизируя положения концепции всеобщего риска можно сделать вывод, что во многих положениях она является разновидностью концепции риска как ресурса с некоторым изменением взгляда на цели управления рисками в виде балансирования между типами производств. Однако, оригинальность использования производственного подхода к риска не позволяет включить данную концепцию к концепции риска как ресурса.

\section{5. Выводы}

Рассмотрение и уточнений положений преобладающих концепций управления рисками сложных организационно-экономических структур, позволили выявить смену парадигм риск-менеджмента, где концепции оперирующие положениями, которые не позволяют оперативно и адекватно принимать управленческие решения в ситуаций возрастающей неопределенности сменяются концепциями, комбинирующие функции менеджмента в сопутствующих видах деятельности в управление рисками систем.

Обобщенная характеристика старой парадигмы управления рисками включает три существенных положения [3]: фрагментарность, эпизодичность и ограниченность риск-менеджмента. Приход новой парадигмы управления рисками сопровождается решением проблем и трудностей предыдущей, которые воплощаются в:

- интегрированном (объединенном) риск-менеджменте;

- непрерывном риск-менеджменте;

- расширенном риск-менеджменте.

Сопоставляя концепции можно сделать вывод, концепция управления рисками, предложенная А. Б. Секериным, полностью отвечает современным требованиям к концепциям новой парадигмы управления рисками сложных организационно-экономических систем. Концепция А. Б. Секерина может быть дополнена и расширена в решении частных задач риск-менеджмента, в том числе адапти- ровании концепции к государственно-частному партнерству, ее модификации.

В связи с этим, последующее развитие теории управления рисками будет направлено на формирование адаптированного подхода к рискам, что позволит нивелировать последствия возрастающей неопределенности среды производственно-хозяйственной деятельности.

Таким образом, систематизация концепций управления рисками позволила определить сущность управленческого воздействия и восприятие рисков в каждом подходе с уточнением достоинств и недостатков концепций, требующих дальнейшее научное развитие.

\section{Литература}

1. Балабанов И. Т. Риск-менеджмент. М.: Финансы и статистика, 1996. - 192 с.

2. Балдин K. B. Риск-менеджмент. М.: Эксмо, 2006. - 368 с.

3. Бартон Т., Шенкер У., Уокер П. Рискменеджмент. Практика ведущих компаний: пер. с англ. - М.: Издательский дом «ВильямС», 2008.

4. Бублик Н. Д., Силантьев В. Б. Рискpeсурс: Проблемы венчурно-стохастической деятельности. - Уфа, 1999.

5. Вяткин В. Н., Гамза В. А., Екатеринославский Ю. Ю., Иванушко П. Н. Управление рисками фирмы. Программы интегративного риск-менеджмента. - М.: Финансы и статистика. $-400 \mathrm{c}$.

6. Гипич Г. Н., Чинючин Ю. М. Введение в теорию рисков. // Научный вестник Московского государственного технического университета гражданской авиации. 2010. — №160. - С. 7-11.

7. Глухих И. Н. Теория систем и системный анализ. - Екатеринбург: Изд-во УрГЭУ, 2003.

8. Грабовый П. Г., Петрова С. Н., Полтавиев С. И., Романова К. Г., Хрусталёв Б. Б., Яровенко С. М. Риски в современном бизнесе. - М.: Аланс, 1994. - 200 с.

9. Качалов Р. М. Управление хозяйственным риском. - М.: Наука, 2002.

10. Клейнер Г. Б., Тамбовиев В. Л., Качалов Р. М. Предприятие в нестабильной экономической среде: риски, стратегия, безопасность. - М.: Экономика, 1997. 
11. Кудрявцев A. A. Интегрированный риск-менеджмент. - М.: Экономика, 2010. - 655 c.

12. Кульман A. А. Экономические механизмы. / Пер с фр.; под общ. редакцией Н. И. Хрусталевой. - М.: Прогресс; Универс, 1993. - 92 с.

13. Маршалл А. Принципы экономической науки: в 3 т. / Пер. с англ. - М., 1993.

14. Милль Дж. С. Основы политической экономии: в 3 т. / Пер. с англ.; общ. ред. А. Г. Милейковского. - М., 1981.

15. Москвин B. A. Управление рисками при реализации инвестиционных проектов. - М.: Финансы и статистика, 2004. - 352 с.

16. Пигу A. C. Экономическая теория благосостояния. / Пер. с англ.; общ. ред. С. П. Аукуционенка. - М., 1985. - С. 5-60.

17. Построение и внедрение системы управления рисками. Примеры из практики АксионБКГ. // Бюллетень CiG Business Consulting. - 2009. - №134.

18. Прокофьев Б. Н. Концепция риска, который никогда не равен нулю. // Энергия. 1989. - №8.

19. Райзберг Б. А. Предпринимательство и риск. - М., 1993. - 56 с.

20. Рогов М. А. Риск-менеджмент. - М.: Финансы и статистика, 2001.

21. Секерин А. Б. Моделирование управления риском как ресурсом и его применения для оптимизации системы налогового контроля. // Вестник МГУ, сер. Экономика. 2004. - №1. - C. 68-83.

22. Секерин А. Б. О методологии управления экономическим риском. // Вестник Воронежского государственного университета. Серия «Экономика и управление». 2004. - №1. - C. 104-111.

23. To Choose or to Loose. National Поступила в редакциюю
Environmental Policy Plan. The Netherlands. // The Netherlands SDU Publishers, 1988.

24. Управление проектом. Основы проектного управления. / Под ред. Разу М. Л. М.: Кнорус, 2006. - 768 c.

25. Федорович $B$. О. Состав и структура организационно-экономического механизма управления собственностью крупных промышленных корпоративных образований. // Сибирская финансовая школа. - 2006. №2. - C. 45-54.

26. Чернова Г. В., Кудрявцев А. А. Управление рисками. - М.: ТК Велби, Изд-во Проспект, 2003. - $160 \mathrm{c}$.

27. Яницкий О. Н. Модернизация России в свете концепции «общества риска» // Куда идет Россия? Общее и особенное в современном развитии. / Под общ. ред. Т. И. Заславской. - М., 1997.

28. Яницкий О. Н. Экологическая политика в «обществе всеобщего риска». // Евразия. Природа и люди. - 1997. - № 2-3.

29. Arrington $J$. R. Руководство по управлению рисками. - TASC, 1993, V. 11-2.

30. Bernstein P. L. Против богов: Укрощение риска. / Пер. с англ. - М.: ЗАО «ОлимпБизнес», 2000. - 400 c.

31. Greenfield M. A. Risk Management: Risk As A Resource, Goddard Space Flight Center, Office of Safety and Mission Assurance, 1997.

32. Keynes J. M. The General Theory of Employment, Interest and Money. - N.Y., 1936.

33. Straus A. G. Managing Risk in PPP Projects though Legal Documentation. Prepared for presentation at the Expert roundtable on private-public partnerships. - Amman, Jordan. 2007, Sept. 6.

34. Tweede Kamer. National Environmental Policy Plan. - The Hague: SDU Publishers (ISSN 0921-7371), 1988-1989.

13 августа 2012 г. 


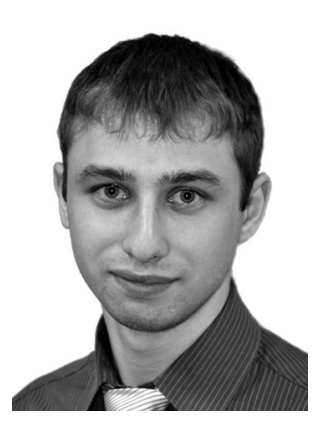

Евгений Анатольевич Кузьмин - аспирант кафедры экономики предприятий Уральского государственного экономического университета. Автор 10 различных объектов интеллектуальной собственности, зарегистрированных Федеральной службой по интеллектуальной собственности РФ, и более 60 научных публикаций.

Область научных интересов: риск-менеджмент, управление предприятиями и организациями, сложные организационные структуры, проектное управление.

Evgueniy Anatolievich Kuzmin - postgraduate student at the Economy of the Enterprise department of the Urals State University of Economics. Author of 10 intellectual property objects, which are recorded by the Russian Federation Intellectual Property Federal Inspection, and more than 60 scientific articles.

Author's field of research interests includes risk management, management of the enterprises and organizations, complex organizational procedures, project management.

620144, г. Екатеринбург, ул. 8 Марта/Народной воли, 62/45

62/45 Vosmogo Marta/Narodnoy Voli st., 620144, Ekaterinburg, Russia

Тел.: +7 (922) 126-72-01; e-mail: KuzminEA@gmail.com 